\title{
Enantiopure, Octadentate Ligands as Sensitizers for Europium and Terbium Circularly Polarized Luminescence in Aqueous Solution
}

Michael Seitz, ${ }^{\dagger}$ Evan G. Moore, ${ }^{\dagger}$ Andrew J. Ingram, ${ }^{\ddagger}$ Gilles Muller, ${ }^{\ddagger}$ Kenneth N. Raymond ${ }^{*} \dagger$

${ }^{\dagger}$ Department of Chemistry, University of California, Berkeley, CA 94720-1460 and Lawrence Berkeley National Laboratory, Berkeley, CA 94720, and ${ }^{\ddagger}$ Department of Chemistry, San José State University, San José, CA 95192-0101.

E-mail: raymond@socrates.berkeley.edu.

\section{Abstract}

Tb and Eu complexes of enantiopure ligands with a new modular design show strong overall luminescence and CPL activity in aqueous solution.

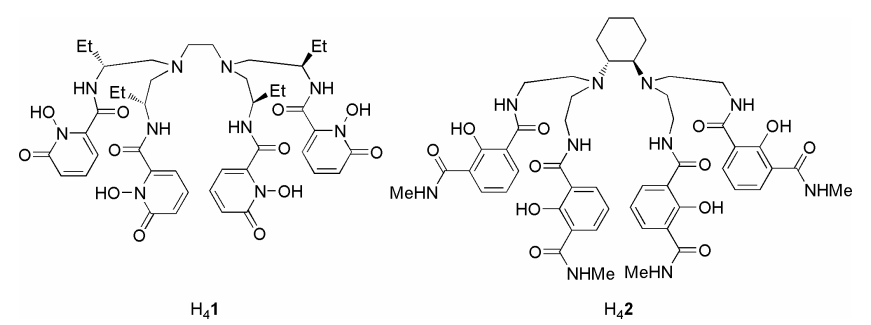

Figure 1. Enantiopure, octadentate ligands.
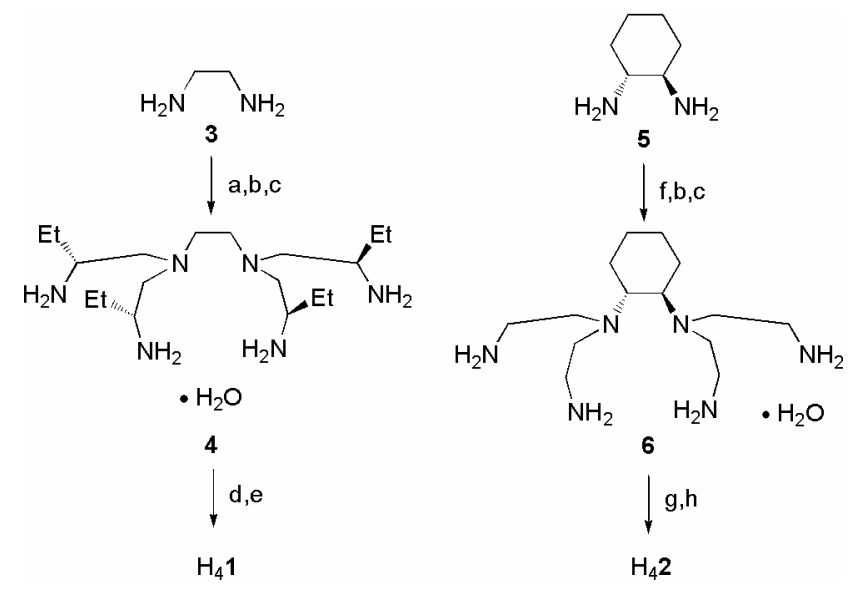

Scheme 1. Synthesis of ligands $\mathrm{H}_{4} 1$ and $\mathrm{H}_{4} 2$. 


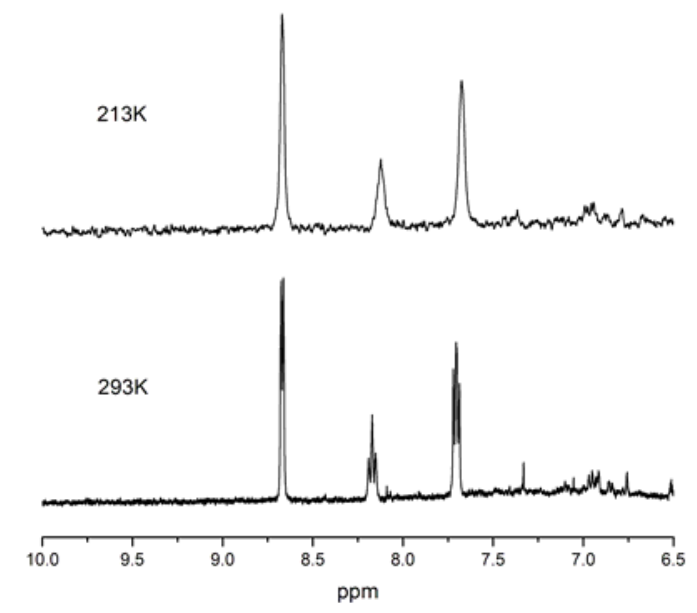

Figure 2. Aromatic region of the ${ }^{1} \mathrm{H}-\mathrm{NMR}$ spectra $(500 \mathrm{MHz})$ of a saturated solution of $\left[\mathrm{Eu}(\mathrm{H} 1)\left(\mathrm{H}_{2} \mathrm{O}\right)\right]$ in $\mathrm{CD}_{3} \mathrm{OD}$ at $293 \mathrm{~K}(\mathrm{bottom})$ and $213 \mathrm{~K}$ (top).

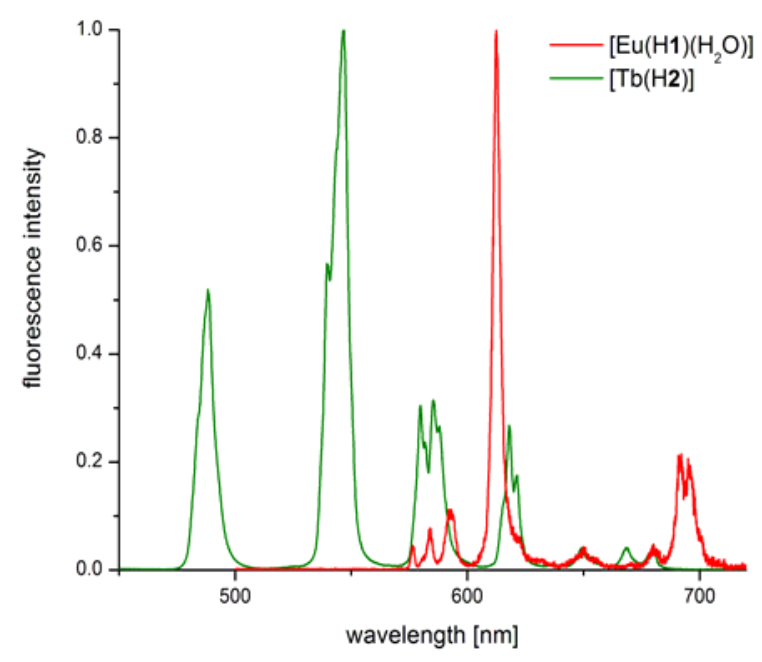

Figure 3. Normalized steady-state emission spectra $\left(\lambda_{\mathrm{exc}}=340 \mathrm{~nm}\right.$, ca. $10^{-5} \mathrm{M}$ in $0.1 \mathrm{M}$ Tris buffer, $\mathrm{pH}$ 7.4).

Table 1. Photophysical properties of the lanthanide complexes (ca. $10^{-5} \mathrm{M}$ in $0.1 \mathrm{M}$ Tris buffer, $\mathrm{pH} 7.4$ ).

\begin{tabular}{lccccc}
\hline \multicolumn{1}{c}{ Complex } & $\begin{array}{c}\lambda_{\max },[\mathrm{nm}] \\
\left(\varepsilon,\left[\mathrm{M}^{-1} \mathrm{~cm}^{-1}\right]\right)\end{array}$ & $\begin{array}{c}\lambda_{\text {exc }}, \\
{[\mathrm{nm}]}\end{array}$ & $\begin{array}{c}\text { Quantum } \\
\text { yield } \Phi^{\mathrm{a}}\end{array}$ & $\begin{array}{c}\text { lifetime } \tau, \\
{[\mathrm{ms}]^{\mathrm{b}}}\end{array}$ & $\mathrm{q}$ \\
\hline$\left[\mathrm{Eu}(\mathrm{H1})\left(\mathrm{H}_{2} \mathrm{O}\right)\right]$ & $341\left(19000^{\mathrm{c}}\right)$ & 340 & 0.077 & $0.48(0.88)$ & 0.84 \\
{$[\mathrm{~Tb}(\mathrm{H} 2)]$} & $339(28200)$ & 340 & 0.57 & $2.28(2.59)$ & -0.04 \\
\hline
\end{tabular}

${ }^{\mathrm{a}}$ Determined relative to quinine sulfate $(\Phi=0.546)$ in $0.5 \mathrm{M}$ sulfuric acid as standard; ${ }^{\mathrm{b}}$ in $\mathrm{H}_{2} \mathrm{O}$ (in $\mathrm{D}_{2} \mathrm{O}$ ); ${ }^{\mathrm{c}}$ sat. solution, estimated $\varepsilon$. 

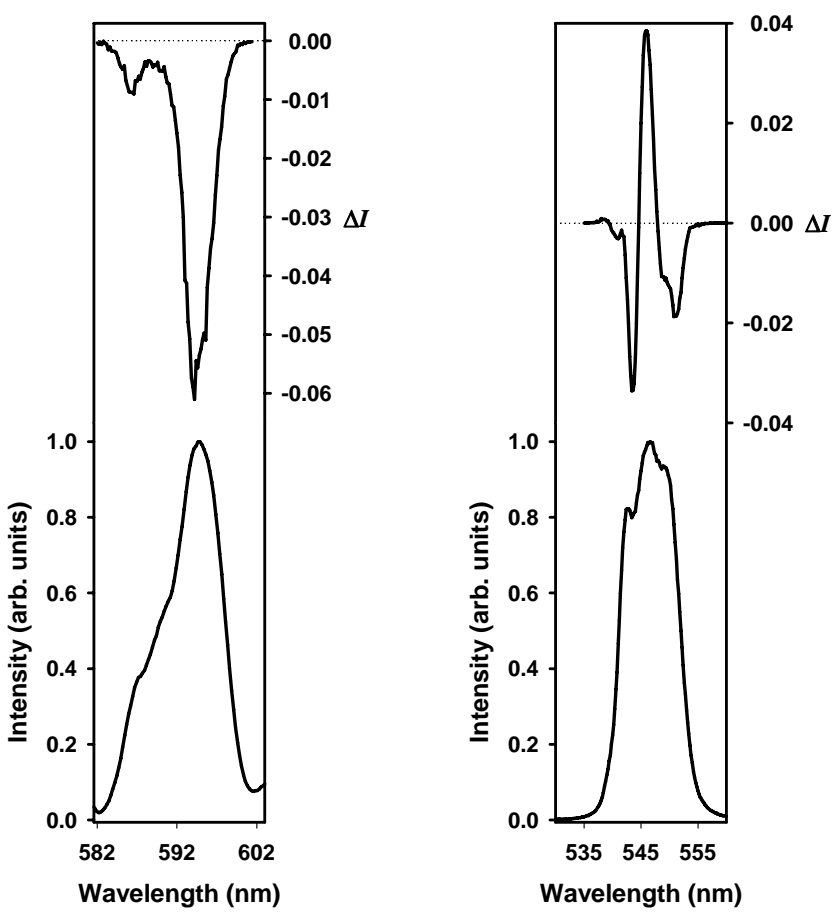

Figure 4. Circularly polarized luminescence (upper curves) and total luminescence (lower curves) spectra of the ${ }^{5} \mathrm{D}_{0} \rightarrow{ }^{7} \mathrm{~F}_{1}$ transition of $[\mathrm{Eu}(\mathrm{H} 1)(\mathrm{H} 2 \mathrm{O})]$ (left) and ${ }^{5} \mathrm{D}_{4} \rightarrow{ }^{7} \mathrm{~F}_{5}$ transition of $[\mathrm{Tb}(\mathrm{H} 2)]$ (right) in saturated aqueous solutions at $\mathrm{pH} 7.4(0.1 \mathrm{M}$ Tris buffer) and $295 \mathrm{~K}$, upon excitation at 360 and $350 \mathrm{~nm}$, respectively.

Table 2. CPL results for lanthanide complexes (saturated aqueous solutions in $0.1 \mathrm{M}$ Tris buffer, $\mathrm{pH}$ 7.4).

\begin{tabular}{lccc}
\hline \multicolumn{1}{c}{ Complex } & Electronic transition & $\lambda[\mathrm{nm}]$ & $\mathrm{g}_{\text {lum }}$ \\
\hline$\left[\mathrm{Eu}(\mathrm{H} \mathbf{1})\left(\mathrm{H}_{2} \mathrm{O}\right)\right]$ & ${ }^{5} \mathrm{D}_{0} \rightarrow{ }^{7} \mathrm{~F}_{1}$ & 586.6 & -0.046 \\
& & 594.2 & -0.12 \\
& & 543.6 & -0.083 \\
{$[\mathrm{~Tb}(\mathrm{H} 2)]$} & ${ }^{5} \mathrm{D}_{4} \rightarrow{ }^{7} \mathrm{~F}_{5}$ & 545.8 & +0.078 \\
& & 551.0 & -0.051 \\
\hline
\end{tabular}

